\title{
OS DIREITOS DE PROPRIEDADE INTELECTUAL DE PROGRAMA DE COMPUTADOR DESENVOLVIDO POR SERVIDOR PÚBLICO DO ESTADO DE SANTA CATARINA
}

\author{
Fabíola Wüst Zibetti ${ }^{1}$ \\ João Alfredo Ziegler Filho
}

Resumo: O presente artigo tem como objetivo analisar a titularidade dos direitos de propriedade intelectual sobre programas de computador desenvolvidos com a colaboração de servidores públicos catarinenses. O estudo aponta que os servidores públicos que colaboram no desenvolvimento de programas de computadores possuem direitos à participação nos ganhos econômicos de sua exploração, contudo há lacunas na regulamentação dessa matéria na legislação catarinense, uma vez que a lei de inovação estadual prevê a concessão de benefícios apenas aos pesquisadores públicos das instituições científicas e tecnológicas do Estado de

1 Doutora em Direito Internacional pela Universidade de São Paulo (USP), com Pós-Doutorado em Direito pelo Programa de Pós-Graduação em Direito da Universidade Federal de Santa Catarina (PPGD/UFSC) e com Pós-Doutorado pelo Centro Ibero-Americano (CIBA), Núcleo de Pesquisa vinculado ao Instituto de Relações Internacional da USP (IRI/USP); Professora da Universidade de Passo Fundo (UPF) e da Faculdade de Integração do Ensino Superior do Cone Sul (FISUL); Pesquisadora dos Grupos de pesquisa: Estudos Avançados de Comércio Exterior e Infraestrutura Logística do Mercosul (EXPOFER/UTFPR); Centro Ibero-americano (CIBA/USP); Grupo de Propriedade intelectual, Desenvolvimento e Inovação (UNESC); Grupo de Propriedade Intelectual, Transferência de Tecnologia e Inovação (PITTI/UFSC). E-mail: fwzibetti@gmail.com

2 Mestrando do Programa de Pós-Graduação em Direito da Universidade Federal de Santa Catarina; Integrante dos Grupos de Pesquisa: Grupo de Propriedade Intelectual, Transferência de Tecnologia e Inovação (PITTI/UFSC); Grupo de Estudos de Segurança Pública (PMSC/UFSC). E-mail: zieglerfilho@gmail.com 
Santa Catarina, sem tratar dos ganhos destinados aos servidores públicos em geral.

Palavras-chave: Programa de computador. Servidor público. Propriedade intelectual. Titularidade.

\section{INTRODUÇÃO}

Com a crescente informatização dos serviços públicos no Brasil, ampliou-se o número de servidores públicos envolvidos no processo de desenvolvimento de softwares para a Administração Pública. Embora grande parte dos programas de computador sejam adquiridos de terceiros, por meio de licenciamento de softwares proprietários, de contratação de obra por encomenda ou de outras formas, há no setor público pessoas dedicadas ao desenvolvimento desses programas ou que acabam se envolvendo em atividades relacionadas a esse processo, como na análise dos requisitos técnicos, no estabelecimento de especificações, na arquitetura, na implementação (codificação), na customização, na realização de testes, na elaboração de documentação, no suporte, no treinamento, na manutenção, entre outras.

Conforme assinala Cláudio SILVA, além das diversas contratações de fornecimento nas três esferas federativas, a Administração Pública conta com servidores cada vez mais capacitados, "que não se acomodam com as soluções oferecidas pela infraestrutura existente e, a todo o momento, criam novas funcionalidades que podem vir a ser incorporadas". ${ }^{3}$

A criação da urna eletrônica no Brasil é um exemplo disso. $\mathrm{O}$ desenvolvimento do projeto da primeira urna eletrônica, chamada então de coletor eletrônico de votos (CEV), envolveu diversos funcionários públicos, como engenheiros e pesqui-

3 SILVA, C. E. R. F. Propriedade intelectual de programa de computador desenvolvido para utilização na administração pública: estudo de caso. Tese (Doutorado em Direito) - Programa de Pós-Graduação em Direito, Universidade Federal de Santa Catarina, Florianópolis, 2013, p. 231. 
sadores ligados ao Centro Técnico Aeroespacial (CTA) e do Instituto Nacional de Pesquisas Espaciais (INPE), dentre outros atores. A complexidade desse processo resultou em disputas judiciais que ainda estão pendentes de solução ${ }^{5}$. Desse caso destaca-se uma problemática que afeta o setor público em todo país: a atribuição da titularidade dos direitos de propriedade intelectual sobre as tecnologias desenvolvidas por servidores públicos e, como consequência disso, se esses servidores teriam direitos a remuneração por conta de suas criações intelectuais.

Com o propósito de aprofundar o debate a respeito dessa temática, levando em consideração o incremento da participação dos funcionários públicos na criação de programas de computador no país, com especial atenção no Estado de Santa Catarina - região na qual se concentram importantes polos tecnológicos especializados no desenvolvimento de softwares -, o presente estudo tem como objetivo analisar a titularidade dos direitos de propriedade intelectual sobre programas de computador desenvolvidos com a colaboração de servidores públicos catarinenses ${ }^{6}$.

O trabalho é desenvolvido em duas partes. Na primeira, são examinadas as formas de proteção dos programas de computador por meio dos direitos de propriedade intelectual, destacando-se as regras gerais de atribuição da titularidade aos

4 Ver CENTRO TÉCNICO AEROESPACIAL (CTA). Instituto de Estudos Avançados (IEAv). Atividades de Pesquisa e Desenvolvimento. São José dos Campos, SP: IEAv/CTA, vol. 1, 2008, p. 16. Disponível em: <http://portal.ieav.cta.br/wp-content/ uploads/caderno_atividades/Caderno_de_Atividades_2008.pdf > Acesso em 10 de agosto de 2014 .

5 Sobre o processo que envolveu a tecnologia da urna eletrônica, sua proteção por patente e demais questões atinentes à titularidade dos direitos, ver SILVA, 2013. Ver ainda o pedido de patente brasileiro: BR9601961 (A) Equipamento para votação eletrônica. Inventor: Moretzsohn Rocha Carlos Cesar. Applicant: Moretzsohn Rocha Carlos Cesar. 1998-09-29. Disponível em: <http://worldwide.espacenet.com/publicationDetails/originalDocument?CC $=\mathrm{BR} \& N R=9601961 \mathrm{~A} \& \mathrm{KC}=\mathrm{A} \& \mathrm{FT}=\mathrm{D} \& N D=3 \&$ date $=$ 19980929\&DB=EPODOC\&locale=en_EP $>$ Acesso em: 05 de agosto de 2014.

60 presente trabalho tem como base o artigo: ZIBETTI, F. W. A titularidade de direitos de propriedade intelectual. In: Luiz Otávio Pimentel. (Org.). A proteção jurídica da propriedade intelectual de software: noções básicas e temas relacionados. Florianópolis: FIESC/ IELSC, 2008, v. 2, p. 81-122. Esse trabalho foi revisado, considerando o novo recorde teórico e metodológico da proposta de pesquisa. 
distintos tipos de direitos. Na segunda, abordam-se especificamente as questões atinentes à titularidade de direitos sobre os programas de computador criados no marco de relação laboral, com ênfase nos funcionários públicos do Estado de Santa Catarina. Nesse ponto, busca-se assinalar a diferença de tratamento dispensada aos servidores públicos em geral em comparação com os pesquisadores públicos - ainda que muitos servidores contribuam para a inovação no setor público, somente os pesquisadores são acolhidos pela legislação específica.

\section{A TITULARIDADE DE DIREITOS DE PROPRIEDADE INTELECTUALSOBREPROGRAMASDECOMPUTADOR}

Os direitos de propriedade intelectual, em sentido amplo, referem-se aos direitos, exclusivos e temporários, garantidos por lei em relação aos frutos da atividade criativa e do engenho humano. Correspondem eles aos direitos conferidos às pessoas sobre suas criações, inventos, marcas, símbolos, nomes e desenhos usados no comércio (WIPO, 2008). Os programas de computador são exemplos de criações protegidas por esses direitos.

O programa de computador caracteriza-se como:

“(...) a expressão de um conjunto organizado de instruções em linguagem natural ou codificada, contida em suporte físico de qualquer natureza, de emprego necessário em máquinas automáticas de tratamento da informação, dispositivos, instrumentos ou equipamentos periféricos, baseados em técnica digital ou análoga, para fazê-los funcionar de modo e para fins determinados". ${ }^{\text {? }}$

7 BRASIL, Lei 9.609/1998, Art. $1^{\circ}$. Essa definição de programa de computador não contempla a documentação associada, tais como o manual de uso e outros documentos técnicos que, em seu conjunto, constituem o software. Em geral, essa documentação apresenta um caráter técnico e, em muitos casos, não é protegida por direitos de propriedade intelectual. Entretanto, conforme cumpram com os requisitos podem ser protegidos como obras literárias ou científicas. Ver ZIBETTI, Fabíola Wüst. A titularidade sobre os bens imateriais. 2008. Dissertação (Mestrado em Direito) - Curso de Pós-Graduação em Direito, Universidade Federal de Santa Catarina, Florianópolis, 2008; AREAS, Patrícia de Oliveira. Contratos inter- 
Em regra, sua proteção opera por meio dos direitos de autor, recaindo sobre a forma de expressão, a linguagem natural ou codificada do programa, como obra literária. Essa proteção não alcança seu conteúdo científico ou técnico ${ }^{8}$. Seu conteúdo, no entanto, quando caracterizado pela inventividade, pode ser objeto de proteção de direitos de propriedade industrial sobre patentes de invenção ou modelos de utilidade. Nesse caso, o programa de computador em si não é protegido, mas tão somente os inventos a ele associados?.

Nesse sentido, de acordo com o tipo de proteção, distintos serão os direitos conferidos e, por efeito, diversas as regras de atribuição de titularidade desses direitos ${ }^{10}$. Essas regras são analisadas a seguir, com base nas distintas formas de proteção: (i) proteção do programa de computador como obra literária e (ii) proteção de invenções associadas a programas de computador.

\subsection{Programa de computador como obra literária}

Nos termos da Lei no 9.609, de 1998, o regime de proteção à propriedade intelectual de programa de computador é o conferido às obras literárias por meio da legislação brasileira de direitos autorais, atentando para as particularidades inerentes ao regime específico de programas de computador ${ }^{11}$.

nacionais de software: o direito moral do autor como limitante da autonomia da vontade. 2006. Dissertação (Mestrado em Direito) - Curso de Pós-Graduação em Direito, Universidade Federal de Santa Catarina, Florianópolis, 2006; PIMENTEL, Luiz Otávio. SILVA, Cláudio Eduardo Regis de Figueiredo e. Conceito jurídico de software, padrão proprietário e livre: políticas públicas. Sequência (Florianópolis) [online]. 2014, n.68, pp. 291-329; VÁZQUEZ LÉPINETTE, Tomás. La cotitularidad de los bienes inmateriales. Valencia: Tirant lo Blanch, 1996, p. 160

8 Ver BRASIL, Lei 9.609/1998, Art. 6 ${ }^{\circ}$ III.

9 Ver BRASIL, Lei 9.279/1996, Art. 10, V e VI.

10 A titularidade exprime a "qualidade de titular". O titular refere-se ao "sujeito ativo, pessoa física ou jurídica, que possui um direito reconhecido ou declarado por lei a seu favor" (PIMENTEL, Luiz Otávio. Propriedade Intelectual e Universidade: aspectos gerais. Florianópolis: Fundação Boiteux, 2005, p. 22-23). A qualidade de titular (ou a titularidade) de direitos é atribuída ao sujeito a quem a lei confere o direito exclusivo de usar, fruir e/ou dispor de um bem, tal como um programa de computador. Desse modo, as demais pessoas, para usá-lo ou explorá-lo comercialmente, dependem de sua autorização (ZIBETTI, 2009, p. 81-122).

11BRASIL, Lei 9.609/1998, Art. $2^{\circ}$, c/c Lei n. 9.610/1998, Artigos. 5, VIII (f), $7^{\circ}, 11$ e 22. 
Dessa forma, sua proteção recai sobre a forma de expressão da linguagem computacional, podendo abranger o título do programa, quando original e inconfundível com o de outro programa do mesmo gênero ${ }^{12}$.

Por ser protegido nos moldes dos direitos autorais, os direitos sobre o programa de computador surgem e se adquirem com o ato de criação, independentemente do registro do programa. Com a criação do programa de computador, emanam-se os direitos de autor, os quais, em princípio, são conferidos ao autor da criação, salvo exceção (obras coletivas e criações de serviço) ${ }^{13}$.

A qualidade de autor (autoria) é atribuída à pessoa física criadora do programa. A autoria não se confunde com a titularidade, embora em muitos possa recair sobre a mesma pessoa. A qualidade de titular (de direitos patrimoniais) pode ser atribuída tanto às pessoas físicas como às pessoas jurídicas, seja de direito público ou privado ${ }^{14}$.

Ainda que, como regra geral, a titularidade dos direitos morais e patrimoniais sobre as criações seja conferida ao autor, a titularidade dos direitos patrimoniais pode ser conferida a sujeito não autor. Nesse caso, ela decorre de imposição legal ou de fato (ou ato), entre vivos ou por causa de morte. Nesse sentido, por exemplo, o cessionário pode ser titular, em virtude de ato de cessão total ou parcial dos direitos de autor, ${ }^{15}$ bem como o herdeiro, por ato de sucessão em decorrência da morte do autor ${ }^{16}$.

12 BRASIL, Lei 9.610/1998, Art. 10. Ainda, importa considerar a possibilidade de registrar o título do programa de computador como marca e, por conseguinte, protege-lo por direito de propriedade industrial de marcas registradas (Ver ZlBETTI, 2008; 2009).

13 BRASIL, Lei n 5.988/1973, Art. 17; Lei 9.609/1998, Art. $3^{\circ}$.

14 BRASIL, Lei 9.609/1998, Art. 2; Lei 9.610/1998, Art. 11 e p.u. Embora sejam distintas, autoria e titularidade são qualidades diretamente relacionadas, pois a identificação do autor de uma criação é essencial para a se conhecer o titular de direitos sobre ela (ZIBETTI, 2008; 2009).

15 BRASIL, Lei 9.609/1998, Art. $2^{\circ}$; Lei 9.610/1998, Art. 49 e ss.

16 BRASIL, Lei 9.609/1998, Art. $2^{\circ}$; Lei 9.610/1998, Art. $24 \S 1^{\circ}$ e Art. 41. 
No caso em que o programa de computador se caracterize como obra derivada (não originária) a atribuição da autoria e a da titularidade devem observar as particularidades estabelecidas na lei. Nessa situação, quando um programa novo resultar da transformação de um programa originário, a proteção do programa de computador derivado será admitida desde que autorizadas pelo titular do programa originário ${ }^{17}$. A derivação é protegida, sem prejuízo dos direitos do autor da obra originária, e, desse modo, o programa de computador derivado tem tutela própria em relação ao programa pré-existente ${ }^{18}$.

O autor do programa originário não se confunde com o autor das derivações do programa. Será autor de programa de computador derivado aquele que realiza a derivação, resguardando-se a autoria do criador do programa originário ${ }^{19}$. Se o programa originário estiver em domínio público, o titular de programa derivado será, em princípio, o autor do novo programa ${ }^{20}$. Se programa originário estiver protegido,

"os direitos sobre as derivações autorizadas pelo titular dos direitos de programa de computador, inclusive sua exploração econômica, pertencerão à pessoa autorizada que as fizer, salvo estipulação contratual em contrário" 21 .

As pessoas qualificadas como autores dos programas originário e derivado não se caracterizam como coautores. Somente poderão concorrer como coautores no caso em que ambas participarem da consecução do novo programa em comum.

Será obra em coautoria o programa de computador criado em comum por dois ou mais autores ${ }^{22}$. No entanto, não

17 BRASIL, Lei 9.609/1998, Art. 20; Lei 9.610/1998, Art. 5.

18 BRASIL, Lei 9.610/1998, Art. 5, VIII, (g). Ver ainda: BRASIL, Lei 9.610/1998, Art. $7^{\circ}, \mathrm{XI}$.

19 BRASIL, Lei 9.609/1998, Art. $2^{\circ}$ e $5^{\circ}$ c/c Lei n. 9.610/1998, Artigos 5², VIII (g), $7^{\circ}$, 11 e 24.

20 BRASIL, Lei 9.609/1998, Art. $2^{\circ}$ e $5^{\circ}$ c/c Lei n. 9.610/1998, Artigos. 5, VIII (g), $7^{\circ}$, 11,14 e 28.

21 BRASIL, Lei 9.609/1998, Art. 5. Ver ainda BRASIL, Lei 9.609/1998, Art. $4^{\circ}$.

22 BRASIL, Lei 9.609/1998, Art. 2º ; Lei n. 9.610/1998, Artigos 5․ VIII (a), $7^{\circ}, 11,15$, 23 e 25. 
basta uma pluralidade de autores participar da criação para o programa se caracterize como obra em coautoria, os diversos autores devem participar da criação do programa de computador empreendendo esforços criativos para a consecução da criação intelectual em comum $^{23}$. De fato, entre os coautores deve constituir-se uma relação horizontal (recíproca), de colaboração ${ }^{24}$. O autor que trabalha de forma independente, sem qualquer relação com os demais, não se caracteriza como coautor ${ }^{25}$.

Quanto à titularidade, em regra, concede-se em comum os direitos sobre o programa de computador a todos os coautores - configurando-se a situação de cotitularidade ${ }^{26}$. Nessa situação, os coautores exercem os seus direitos de comum acordo, salvo convenção em contrário ${ }^{27}$.

\subsection{Inventos associadas a programas de computador}

Ademais da proteção do programa de computador em si, em alguns casos, é possível a proteção de inventos associadas a

23 POLLAUD-DULIAN, Frédéric. Le Droit D'Auteur. Paris: Economica, 2005, p. 184; SAIZ GARCÍA, Concepción. Objecto y sujeto del derecho de autor. Valencia: Tirant lo Banch, 2000.

24 HUGUET, André. L'ordre public et les contrats d'exploitation du droit d'auteur. Paris: LGDJ, 1962.

25 Para se determinar a coautoria, não se leva em conta somente a participação dos autores durante a criação, mas suas contribuições mútuas, ou seja, os esforços reunidos de cada um dos coautores para a consecução de um trabalho criativo comum. Na prática nem sempre é simples determinar a qualidade do esforço empreendido pelas pessoas, sendo necessário se avaliar caso a caso (ZIBETTI, 2009). Ver V VILLALBA, Carlos A.; LIPSZYC, Delia. El derecho de autor en la Argentina. Buenos Aires: La Ley, 2001, p. 69-70. Além dos aspectos qualitativos das contribuições que merecem ser apreciados caso a caso, importa observar os aspectos temporais, uma vez que a contribuição deve ser empreendida durante o período de consecução do programa, em quaisquer das fases de sua elaboração, e não posteriormente a sua criação, momento posterior à conclusão da obra (Ver LUPI, André Lipp Pinto Basto. Proteção Jurídica do Software: Eficácia e Adequação, Ed. Síntese, 1998, p. 21; AREAS, 2006; WACHOWICZ, 2004; BRASIL. Tribunal de Alçada de Minas Gerais. Apelação Cível 0431374-6/2003. Apelante: Alma Informática Ltda. Apelado: Virgílio Cançado Paculdino Pereira. Segunda Câmara Cível. Relator: Juíza Evangelina Castilho Duarte. Julgado em 16/03/2004; ver VAZQUEZ LEPINETTE, 1996, p. 165). Quem intervém somente na fase de exploração da obra, não se caracteriza como coautor (SAIZ GARCÍA, Concepción. Objecto y sujeto del derecho de autor. Valencia: Tirant lo Banch, 2000, p. 179-180).

26 Ver ZIBETTI, 2008.

27 BRASIL, Lei n. 9.610/1998, Art. 23. 
programas de computador. Ainda que a Lei no 9.279 de 1996, que regula os direitos e as obrigações relativos à propriedade industrial, considere que os programas de computador em si não se caracterizam como inventos ${ }^{28}$, podem haver inventos que envolvam programa de computador para sua realização. Esses inventos podem ser protegidos por meio de patentes de invenção ou de modelos de utilidade ${ }^{29}$.

São patenteáveis as invenções relativas a produtos (entidade física) ou processo (atividade), caracterizadas pela novidade, atividade inventiva (não evidentes para um técnico na matéria) e aplicação industria ${ }^{30}$. Há diversos exemplos de invenções envolvendo programas de computador patenteadas, como sistemas de processamento de imagem, filtros de som e imagem, controles de processos industriais, entre outros ${ }^{31}$.

Ainda, são patenteáveis como modelo de utilidade os objetos de uso prático, ou parte destes, suscetíveis de aplicação industrial, que apresentem nova forma ou disposição, envolvendo ato inventivo, cujo resultado consista em melhoria funcional no seu uso ou em sua fabricação ${ }^{32}$. Servem de exemplos desse tipo de invento os artigos de utilidade, ferramentas e utensílios de trabalho ou de uso, como equipamentos e suportes

28 BRASIL, Lei $n^{\circ}$ 9.279/1996, Art. 10, V; Ver ainda Art. 10, VI.

29 BRASIL, Lei $n^{\circ} 9.279 / 1996$, Art. $2^{\circ}$, I.

30 BRASIL, Lei n 9.279/1996, Artigos 8, 11, 12 e 13.

31 Como exemplos, os pedidos e patentes: BRPI9305030-5, "Método para processamento e filtragem digitais de sinais em aplicações de controle industriais"; BRPI9611518-1, "Método de alinhamento de códigos legíveis por máquina para pixels de impressora"; US5715314, "Network sales system"; US5808623, "System and method for perspective transform in computer using multi-pass algorithm"; US5897620: "Method and apparatus for the sale of airline-specified flight tickets" (EUROPEAN PATENT OFFICE (EPO). Espacenet. Patent search. Disponível em: <http://www.epo.org/searching/free/espacenet.html> Acesso em: 12 de agosto de 2014). Em geral, o programa de computador refere-se à tecnologia de processo (GEIGER, Christophe; Hilty, R.M. Patenting Software? A Judicial and Socio-Economic Analysis. IIC, 2005, Vol. 36, p. 615-647), mas é possível se identificar diversas tecnologias de produção que se relacionam a programas de computador.

32 BRASIL, Lei $n^{\circ}$ 9.610/1998, Art. $9^{\circ}$. O modelo de utilidade protege a funcionalidade da forma ou disposição do objeto (produto), ou seja, a proteção se volta ao valor funcional (e não do valor estético ou ornamental) da configuração externa do produto. 
físicos (hardwares) no qual se insere o programa, bem como as interfaces gráficas ${ }^{33}$.

$\mathrm{Na}$ Classificação Internacional de Patentes existem várias classes que guardam relação direta com tecnologias de produtos e processos que envolvem programas de computador, como: G06N (sistemas de computador baseados em modelos computacionais específicos), G06F 17/00 e G06F 19/00 (equipamentos ou métodos de computação digital ou de processamento de dados, especialmente adaptados para funções específicas); B60L 15/00 (Métodos, circuitos ou dispositivos para controlar a velocidade do motor de tração de veículos de propulsão elétrica), B21B 37/24 (Variação automática da espessura de acordo com um programa predeterminado (Dispositivos de controle ou métodos especialmente adaptados para laminadores ou o trabalho produzido pelos mesmos)); B41F 33/16 (sistemas de programação para controle automático da seqüência de operações (Dispositivos indicadores, de contagem, de alarme, de controle ou de segurança)); G06G 7/06 (Disposições para programação, por ex., painel de ligações para interligar unidades funcionais do computador; Programação digital ${ }^{34}$.

Distintamente do regime de proteção de programas de computador pelos direitos autorais, as invenções e os modelos de utilidade são tutelados por direitos de propriedade industrial, os quais são adquiridos com a concessão válida da patente ${ }^{35}$.

Com o ato de invenção, surge o direito de requere a patente que, em princípio, é assegurado ao autor do invento - pessoa física que realiza o ato de invenção -, salvo exceções (e.g. criações de serviço). A qualidade de autor do invento é atribuída à pessoa física que realiza a atividade inventiva, independentemente dos meios utilizados e fins pretendidos ${ }^{36}$.

33 Ver MIRANDA, Pontes de. Tratado de Direito Internacional Privado. 4 ed. São Paulo: Revista dos Tribunais, 1983, p. 406.

34 WORLD INTELLECTUAL PROPERTY ORGANIZATION (WIPO). International Patent Classication (IPC) Official Publication. Disponível em: <http://ipc.inpi.gov. br/ipcpub/\#refresh=page> Acesso Em: 10 de agosto de 2014 .

35 BRASIL, Lei n. 9.279/1996, Art. $6^{\circ}$, e $\S 3^{\circ}$ e $\S 2^{\circ}$.

36 Ver MIRANDA, 1983, p. 271. CABANELLAS DE LAS CUEVAS, Guillermo. Derecho de las patentes de invención. 2 ed. Buenos Aires, 2004, p. 26-27. 
O autor do invento, denominado inventor, é a figura central para se analisar a titularidade de direitos de patente, uma vez que o direito à proteção da invenção por meio de patente surge na sua figura. Esse direito pode ser transferido, antes do pedido ou da concessão da patente, a outra pessoa por qualquer meio admitido por Direito. Desse modo, pode assumir a qualidade de titular do direito de obter a patente e, destarte, do direito de propriedade industrial sobre a patente concedida, tanto o inventor como outra pessoa por ele legitimada, seja por imposição legal ou por ato, entre vivos ou por causa de morte ${ }^{37}$. Portanto, pode ser titular qualquer pessoa, física ou jurídica, seja de direito público ou privado ${ }^{38}$.

A proteção conferida pela patente de invenção ou de modelo de utilidade recai sobre o efeito técnico do invento, e a extensão da proteção é determinada pelo teor das reivindicações, interpretado com base no relatório descritivo e nos desenhos. Esses documentos (reivindicações, relatório descritivo e desenhos) fazem parte do conjunto de documento técnicos contidos no pedido de patentes ${ }^{39}$. Dentre os documentos exigidos, porém, não se inclui a descrição do código fonte do programa, ou seja, o programa em si.

$\mathrm{O}$ invento também pode ser resultado de uma criação em coautoria. Nesse caso, será caracterizado como coinvenção, ou seja, quando duas ou mais pessoas realizam um invento conjuntamente na qualidade de coautores. São coautores as pessoas que participaram empreendendo esforços conjuntamente para a consecução da invenção. Essa participação consubstancia-se e se expressa nas reivindicações da patente, as quais determinam à extensão da proteção da patente ${ }^{40}$. Não se consideram coinven-

37 BRASIL, Lei 9.279/1996, Art. $8^{\circ}$ a 15.

38 BRASIL, Lei $9.610 / 1998$, Art. $7^{\circ}$. O direito de obter a patente é assegurado à pessoa legitimada que primeiro realizar o pedido, independentemente da data da invenção. Independentemente de quem seja o titular dos direitos, garante-se ao inventor o direito de ser nomeado e qualificado como tal na patente (BRASIL, Lei 9.279/1996, Art. $6^{\circ}$, e $\S 3^{\circ}$ e $\S 2^{\circ}$ ).

39 BRASIL, Lei 9.279/1996, Art. 41 e 19.

40 BRASIL, Lei 9.279/1996, Art. 41. 
tores os inventores independentes, ainda que realizem invento igual ou semelhante ${ }^{41}$.

Na coinvenção, o direito de obter a patente é concedido em comum a todos os coautores. A patente pode ser requerida por todos ou qualquer dos coinventores, mediante nomeação e qualificação dos demais, para ressalva dos respectivos direitos ${ }^{42}$. Nessa situação, em regra, configura-se o regime de cotitularidade de patente, em que cada um dos coinventores é titular de quota ideal do direito de patente de invenção ${ }^{43}$.

Em síntese, conforme se apresenta no Quadro 1 a seguir, a regra geral de atribuição da titularidade de direitos das criações passíveis de proteção por direitos de propriedade intelectual é a regra da autoria, em que o autor da criação ou invento é caracterizado como titular de direitos.

\begin{tabular}{|c|c|c|c|}
\hline \multicolumn{4}{|c|}{$\begin{array}{l}\text { Quadro } 1 \text { - Regra geral de atribuição de titularidade sobre } \\
\text { bens protegidos por direitos de propriedade intelectual }\end{array}$} \\
\hline $\begin{array}{l}\text { Tipo de } \\
\text { criação }\end{array}$ & Proteção & Regime das obras & Titularidade \\
\hline \multirow{3}{*}{$\begin{array}{l}\text { Programa de } \\
\text { computador }\end{array}$} & \multirow{3}{*}{$\begin{array}{l}\text { Não exige } \\
\text { registro }\end{array}$} & $\begin{array}{l}\text { Programa de computador } \\
\text { (autoria singular) }\end{array}$ & Do autor \\
\hline & & $\begin{array}{l}\text { Programa de computador } \\
\text { derivado }\end{array}$ & $\begin{array}{l}\text { Do autor do } \\
\text { programa derivado }\end{array}$ \\
\hline & & $\begin{array}{l}\text { Programa de computador } \\
\text { em coautoria }\end{array}$ & Dos coautores \\
\hline \multirow{2}{*}{ Invenção } & \multirow{2}{*}{$\begin{array}{l}\text { Exige } \\
\text { concessão } \\
\text { de patente }\end{array}$} & Invenção (autoria singular) & \multirow{4}{*}{$\begin{array}{l}\text { Do primeiro autor } \\
\text { (ou coautores) } \\
\text { ou pessoa por } \\
\text { ele legitimada a } \\
\text { requerer a patente }\end{array}$} \\
\hline & & Coinvenção (coautoria) & \\
\hline \multirow{2}{*}{$\begin{array}{l}\text { Modelo de } \\
\text { utilidade }\end{array}$} & \multirow{2}{*}{$\begin{array}{l}\text { Exige } \\
\text { concessão } \\
\text { de patente }\end{array}$} & $\begin{array}{l}\text { Modelo de utilidade } \\
\text { (autoria singular) }\end{array}$ & \\
\hline & & $\begin{array}{l}\text { Modelo de utilidade em } \\
\text { coautoria }\end{array}$ & \\
\hline
\end{tabular}

Fonte: adaptado de ZIBETTI, 2009, p. 100.

41 BRASIL, Lei 9.279/1996, Art. $7^{\circ}$.

42 BRASIL, Lei 9.279/1996, Art. $6^{\circ}, \S 3^{\circ}$.

43 FISCHER, Frank. O Regime de copropriedade em patentes. Disponível em: $<$ www.dannemann.com.br/files/FFI_Regime_de_CoPropriedade_em_Patentes. pdf>. Acesso em: 10 de julho de 2014; VÁZQUEZZ LEPINETTE, 19̄96, p. 66. 
Essa regra geral de atribuição da titularidade de direitos de propriedade intelectual, no entanto, é excepcionada quando por lei ou por fato (ou ato), entre vivos ou por causa de morte, os direitos são adquiridos ou se transferem a outras pessoas distintas do autor, tão logo se realize a criação. Esse é o caso das criações decorrentes de contrato de trabalho ou prestação de serviço que implicam na atribuição da titularidade ao empregador ou tomador de serviço ${ }^{44}$. Na seção seguinte é analisada a titularidade das criações ocorridas no âmbito da relação de trabalho, com especial atenção aos programas de computador desenvolvidos com a colaboração de funcionários públicos catarinenses.

\section{A TITULARIDADE DAS CRIAÇÕES OCORRIDAS DURANTE A RELAÇÃO LABORAL: OS FUNCIONÁRIOS PÚBLICOS CATARINENSES}

As criações decorrentes de relação contratual de trabalho ou de prestação de serviços são muito freqüentes e, na prática, assumem distintas denominações, tais como obras por encomenda e obras por encargo. Essas relações podem implicar diretamente na atribuição da titularidade aos sujeitos envolvidos.

No caso dos programas de computador, ainda que se apliquem a eles as disposições das obras literárias, a Lei n. 9.609/1998 prevê regras específicas a respeito da titularidade das criações ocorridas durante contrato de trabalho. A lei de programa de computador estabelece um regime próprio de atribuição da titularidade ${ }^{45}$. Esse regime assemelha-se ao de invenções e modelos de utilidade previstas na lei de propriedade industrial ${ }^{46} \mathrm{e}$, dessa maneira, podem ser analisadas conjuntamente ${ }^{47}$.

44 "Ainda, pode ocorrer, por exemplo, a transferência da titularidade por cessão, total ou parcial, ou sucessão, por causa de morte ou por extinção de pessoa jurídica. Anota-se que no caso de autorização de uso ou exploração, de licenciamento ou concessão, exemplificativamente, não há transferência de titularidade, não sendo o licenciado qualificado como titular propriamente dito" (ZIBETTI, 2009).

45 BRASIL, Lei 9.609/1998, Art. $4^{\circ}$.

46 BRASIL, Lei 9.279/1996, Art. 88 a 93, regulamentados pelo Decreto 2.553/1998.

47 Aplica-se a ambos também as disposições da lei de incentivo à inovação, Lei $10.973 / 2004$. 
Com relação às criações (programa de computador, invenções e modelo de utilidade) ocorridas durante contrato de trabalho, elas podem ser caracterizadas como "criação de serviço", "criação livre” ou "criação comum”. Essa terminologia não é utilizada pela lei, mas pela doutrina que trata dessa matéria.

As "criações livres" são aquelas ocorridas durante o contrato de trabalho, mas que não decorrem do contrato, nem do uso de recursos, informações tecnológicas, segredos industriais e de negócios, materiais, instalações ou equipamentos do empregador. Nessa hipótese, a titularidade dos direitos sobre o bem é atribuída exclusivamente ao empregado ${ }^{48}$. A legislação faz referência ao empregado, contudo, seu conceito também se estende ao prestador de serviço, ao trabalhador autônomo, ao estagiário e ao funcionário público da Administração Pública, direta, indireta e fundacional, federal, estadual ou municipal ${ }^{49}$.

No caso do servidor público, ainda que ele tenha colaborado na elaboração de programa de computador de interesse da Administração Pública, mas sem ter sido contratado para isso, a titularidade dos direitos de propriedade intelectual sobre o programa não se desloca para o empregador público. Nos termos da legislação estatutária catarinense, uma vez que o funcionário tem sua remuneração conformada com suas atribuições e, considerando que entre elas não se inclui o desenvolvimento de programas de computador, não se pode conferir a titularidade à Administração Pública, pois "é proibida a prestação de serviços gratuitos ao Estado"..$^{50}$ Ainda, cabe destacar que "é vedado atribuir ao funcionário outros serviços, além dos inerentes ao cargo de que seja titular, exceto quando designado, mediante gratificação, para o exercício de função de confiança

48 BRASIL, Lei 9.609/1998, Art. 4º, § 2; Lei 9.279/1996, Art. 90.

49 BRASIL, Lei 9.279/1996, Art. 93. Nos termos do Estatuto dos Servidores Públicos Civis do Estado de Santa Catarina, o funcionário público "é a pessoa legalmente investida em cargo público criado por lei, de provimento efetivo ou em comissão, com denominação, função e vencimento próprios, número certo e pagamento pelo erário estadual" (SANTA CATARINA, Lei 6.745/1985, Art. $2^{\circ}$ ).

50 SANTA CATARINA, Lei 6.745/1985, Art. $3^{\circ}$. 
ou para integrar grupos de trabalho ou estudo, criados pela autoridade competente". ${ }^{51}$

Portanto, se o funcionário público não possui entre suas funções a de desenvolvimento de software ou atividade correlata, caso ele se envolva no processo de criação e elaboração de um programa de computador para a Administração Pública informalmente, sem contrato prévio, a titularidade dos direitos sobre o programa poderá ser atribuída ao funcionário.

No entanto, se o funcionário, ao se envolver no desenvolvimento de programas de computador, mesmo sem que esta atividade faça parte de suas atribuições, utilize de recursos da Administração Pública, nesse caso estaremos frente a uma "criação comum".

As "criações comuns" referem-se àquelas que resultam da contribuição pessoal do empregado e de recursos, dados, informações, meios, materiais, instalações ou equipamentos do empregador, ressalvada expressa disposição contratual em contrário $^{52}$. Os direitos sobre essas criações pertencerão em comum, em partes iguais, ao empregado e empregador, constituindo uma situação de cotitularidade (e não de coautoria entre empregado e empregador). Sendo mais de um empregado, a parte que lhes couber será dividida igualmente entre todos, salvo ajuste em contrário ${ }^{53}$.

Ainda que se caracterize a cotitularidade entre empregador e empregado, assegura-se ao empregador o exercício do direito exclusivo de licença de exploração, garantindo ao empregado justa remuneração ${ }^{54}$. Na ausência de acordo, a exploração do objeto da patente deve ser iniciada pelo empregador dentro do prazo de um ano, contado da data de sua concessão, sob pena

51 SANTA CATARINA, Lei 6.745/1985, Art. $4^{\circ}$.

52 BRASIL, Lei 9.279/1996, Art. 91; Lei 9.609/1998, Art. 4 §2.

53 Conforme o Art. 91, da Lei n 9.279/1998. Em relação à proteção dos programas de computador em si, aplica-se subsidiariamente a legislação de propriedade industrial.

54 BRASIL, Lei 9.279/1998, Art. 91, §2. No caso de cessão, qualquer dos cotitulares, em igualdade de condições, poderá exercer o direito de preferência (BRASIL, Lei 9.279/1998, Art. 91, §4º). 
de passar à exclusiva propriedade do empregado a titularidade da patente ${ }^{55}$.

No caso das criações decorrentes de atribuições previstas no contrato de trabalho, elas se caracterizam como "criações de serviço". Em situações que a criação decorra contrato de trabalho que tenha por objeto a pesquisa e desenvolvimento ou a atividade inventiva ou, ainda, quando resultar da natureza dos serviços para os quais foi o empregado contratado, a legislação estipula que a titularidade dos direitos patrimoniais sobre a criação é do empregador ${ }^{56}$, resguardando-se aos autores seus direitos morais ${ }^{57}$.

Como regra geral, sendo a titularidade do empregador, a retribuição do empregado pela criação limita-se à remuneração ou ao salário convencionado, salvo ajuste em contrário ${ }^{58}$. Portanto, a legislação admite que as partes (contratante e contratado) convencionem de forma distinta do previsto em lei, seja no tocante à titularidade e/ou à remuneração. Nesse caso, pode o empregador:

- Garantir ao empregado uma remuneração adicional, além da remuneração ou do salário convencionado;

- Assegurar ao empregado contratado o exercício de direitos patrimoniais (e.g. por meio de licença), que pode se limitar a algumas das modalidades de exercício, como o uso ou explo-

55 BRASIL, Lei 9.279/1998, Art. 91, §3 , Lei 9.279/1998.

56 BRASIL, Lei 9.609/1998, Art. $4^{\circ}$, caput; Lei nº 9.279/1996, Art. 88. Consideram-se desenvolvidos na vigência do contrato a invenção ou o modelo de utilidade cuja patente seja requerida pelo empregado até um ano após a extinção do vínculo empregatício, ressalvada prova em contrário (BRASIL, Lei 9.279/1996, Art. 88, § $2^{\circ}$ ).

57 Asseguram-se ao autor do invento ou do programa de computador o direito de reivindicar a autoria e o de ser nomeado e qualificado, podendo requerer a não divulgação de sua nomeação. Esses direitos pertencem ao autor (empregado contratado), na medida da sua participação na criação intelectual. Esses direitos são irrenunciáveis e inalienáveis, não se transferindo ao empregador, sendo nula qualquer cláusula contratual em que o empregado renuncie ou ceda esses direitos (BRASIL, Lei 9.610/1998, Art. 24 e 27). Ver BRASIL, Lei 9.609/1998, Art. $2^{\circ}$, § 10; Lei 9.279/1996 Art. $6^{\circ}, \S 4^{\circ}$.

58 BRASIL, Lei 9.609/1998, Art. $4^{\circ}, \S 1^{\circ}$. 
ração do programa de computador, invenção ou modelo de utilidade;

- Estipular uma quota ideal do direito, constituindo-se um regime de cotitularidade entre empregado e empregador; ou

- Ceder seu direito sobre a criação ${ }^{59}$.

Com relação aos servidores da Administração Pública direta, indireta e fundacional, há regras específicas sobre a matéria. Nesse caso, aplica-se o Decreto $\mathrm{n}^{\circ}$ 2.553, de 1998, que regulamenta a lei de propriedade industrial. Embora ele se destine a regular os dispositivos 88 a 93 da Lei no 9.279 , que trata dos direitos de propriedade industrial, considera-se que pode ser aplicado subsidiariamente para regular o Art. $4^{\circ}$ da Lei no 9.609 , de 1998, que dispõe sobre a proteção da propriedade intelectual de programa de computador.

Nos termos desse Decreto, ao servidor público que desenvolver invenção, aperfeiçoamento ou modelo de utilidade e desenho industrial, assegura-se premiação de parcela - que não pode exceder a um terço - do valor das vantagens auferidas pelo órgão ou entidade com a exploração da patente ou do registro, a título de incentivo, durante toda a vigência da patente ou do registro ${ }^{60}$.

Os parâmetros em relação a essa premiação não são estabelecidos pelo Decreto, cabendo aos órgãos e às entidades da Administração Pública inserir normas em seus estatutos ou regimentos internos que definam a forma e as condições de pagamento dessa premiação ${ }^{61}$. No Estado de Santa Catarina, no entanto, não se identificam normas específicas sobre essa matéria. Com exceção dos funcionários de instituições científicas e tecnológicas do Estado, aos quais se aplica a lei catarinense de inovação ${ }^{62}$, aos demais servidores públicos não há

59 Ver BRASIL, Lei 10.973/2004, Art. 11.

60 BRASIL, Decreto 2.553/1998, Art. 3º $§ 2^{\circ}$. Ver ainda: BRASIL, Lei 9.279/1996, Art. 93, p.u. e art. 88.

61 BRASIL, Decreto 2.553/1998, Art. $3^{\circ}, \S^{\circ}$.

62 SANTA CATARINA, Lei 14.328/2008. 
disposições a esse respeito na legislação estatutária ${ }^{63}$ nem nos estatutos ou regimentos internos de órgãos e entidades públicos.

Quanto às invenções realizadas no âmbito das instituições científicas e tecnológicas da Administração Pública, a legislação federal assegura ao autor a participação mínima de 5\% e máxima de um terço nos ganhos econômicos auferidos pela instituição. Esses ganhos podem resultar de contratos de transferência de tecnologia ou de licenciamento para outorga de direito de uso ou de exploração da criação protegida ${ }^{64}$. Entende-se como criação não apenas as invenções e modelos de utilidade, como também os programas de computador, dentre outros desenvolvimentos tecnológicos que acarretem ou possam acarretar o surgimento de novo produto, processo ou aperfeiçoamento incremental ${ }^{65}$

$\mathrm{Na}$ esfera estadual, o Estado de Santa Catarina possui norma semelhante à federal, ainda que não contemple a mesma margem de benefícios ao pesquisador público. De acordo a lei de inovação catarinense, ao pesquisador público é assegurada participação mínima de $5 \%$ e máxima de $25 \%$ nos ganhos econômicos auferidos pela instituição ${ }^{66}$. Ainda que essa norma não faça referência expressa aos programas de computadores criados por servidores de instituições científicas e tecnológicas estaduais, considera-se que implicitamente ela os abarque na definição de criação, uma vez que faz referência às criações que podem "acarretar o surgimento de novo produto, processo ou aperfeiçoamento incremental". ${ }^{67}$

63 SANTA CATARINA, Lei 6.745/1985; ver ainda Constituição do Estado de Santa Catarina de 1989.

64 BRASIL, Art. 13, Lei 10.973/2004; Lei 9.279/1996, Art. 93, p.u. Esses ganhos econômicos referem-se a "toda forma de royalties, remuneração ou quaisquer benefícios financeiros resultantes da exploração direta ou por terceiros, deduzidas as despesas, encargos e obrigações legais decorrentes da proteção da propriedade intelectual", resultantes de contratos de transferência de tecnologia ou de licenciamento para outorga de direito de uso ou de exploração do invento (BRASIL, Lei 10.973/2004, Art. 13 e $\S 2^{\circ}$; Lei 9.279/1996, Art. 93, p.u.). Ver ainda: BARBOSA, Denis Borges. Direito da inovação: comentários à lei n 10.973/2004, Lei Federal da Inovação. Rio de Janeiro: Lumen Juris, 2006

65 BRASIL, Lei 10.973/2004, Art. $1^{\circ}$, II.

66 SANTA CATARINA, Lei 14.328/2008, Art. 15 e $\S 2^{\circ}$.

67 SANTA CATARINA, Lei 14.328/2008, Art. 2, VII, VIII e IX. 
Na prática nacional, divergem as soluções adotadas para o cálculo dessa premiação pela Administração Pública, tanto aos pesquisadores como aos demais servidores públicos. Conforme o uso destinado à criação, há aqueles que determinam como parâmetro o salário ajustado, enquanto outros consideram a participação nos ganhos econômicos resultantes da exploração da patente, por exemplo. Qualquer que seja o valor ou a forma dessa participação, ela não se incorpora, a qualquer título, aos salários dos empregados ou aos vencimentos dos servidores ${ }^{68}$. Sobre essa questão há várias decisões proferidas pelo Tribunal Superior do Trabalho (TST) ${ }^{69}$.

Ainda, no que se refere às criações dos empregados públicos, importa destacar que o entendimento dessa Corte é que o empregador "está obrigado, por lei, a remunerar o autor do invento. Irrelevante o fato de o empregado patentear, ou não, o invento". ${ }^{70}$

Considerando a análise realizada nessa seção, observa-se que os programas de computador desenvolvidos com a colaboração de servidores públicos, incluindo-se os inventos a eles associados, podem ser caraterizados como "criações de serviço", "criações livres" ou "criações comuns", correspondendo à titula-

68 BRASIL, Lei 9.279/1996, Art. 89, p.u.; Decreto 2.553/1998, Art. $4^{\circ}$.

69 BRASIL. Tribunal Regional Federal de $4^{\text {a }}$ Região. Agravo de instrumento $n^{\circ}$ 200404010216989 PR. Rel. Vânia Hack de Almeida, $3^{a}$ Turma. Data da decisão: 07/11/2005. DJU - 30/11/2005, p. 721; BRASIL. Tribunal Superior do Trabalho. Recurso de Revista TST-RR-749.341/01.5. Recorrentes: Rede Ferroviária Federal S/A e Ferrovia Centro Atlântica S/A. Recorrido: Marcos Penha Menezes. Primeira Turma. Relator: Ministro João Oreste Dalazen. Brasília, 9/8/2006. DJ 06/10/2006; BRASIL. Tribunal Superior do Trabalho. Recurso Ordinário em Ação Rescisória TST-ROAR-752911/2001.7. Recorrente: Usiminas Mecânica S/A. Recorrido: Juan Elias Lepe Yevenes. Subseção II Especializada em Dissídios Individuais Relator: Ministro José Simpliciano Fontes de F. Fernandes. Brasília, 28/11/2006. DJ de 19/12/2006; BRASIL. Tribunal Superior do Trabalho. Primeira Turma. Reapreciação de Recurso de Revista TST-RRR-1.426/79. Rel. Juiz Convocado Sebastião Machado Filho. Brasília, DJU de 25.11.88, p. 31.160; BRASIL. Tribunal Superior do Trabalho. Quarta Turma. Agravo de Instrumento em Recurso de Revista TST-AIRR - 433/1986-001-17-00. Agravante: Companhia Vale do Rio Doce. Agravado: Francisco Chagas Marques dos Santos. Relator: Milton de Moura França. Brasília, 14/4/2004. DJ de 30/04/2004.

70 BRASIL. Tribunal Superior do Trabalho. Recurso de Revista TST-RR-749.341/01.5. Recorrentes: Rede Ferroviária Federal S/A e Ferrovia Centro Atlântica S/A. Recorrido: Marcos Penha Menezes. Primeira Turma. Relator: Ministro João Oreste Dalazen. Brasília, 9/8/2006. DJ - 06/10/2006. 
ridade ao empregador, ao empregado ou em comum ao empregado e empregador, respectivamente. No Quadro 2, abaixo, apresenta-se uma síntese dessas regras.

\begin{tabular}{|c|c|c|}
\hline \multicolumn{3}{|c|}{$\begin{array}{c}\text { Quadro } 2 \text { - Da criação (invenção) ocorrida durante con- } \\
\text { trato de trabalho ou de prestação de serviço: disposições } \\
\text { na legislacão brasileira }\end{array}$} \\
\hline $\begin{array}{c}\text { Tipo de obra / } \\
\text { Hipóteses }\end{array}$ & $\begin{array}{l}\text { Programa de } \\
\text { computador }\end{array}$ & $\begin{array}{c}\text { Invenção e modelo de } \\
\text { utilidade }\end{array}$ \\
\hline \multirow{3}{*}{$\begin{array}{l}\text { (1) Resultar de contrato } \\
\text { que tenha por objeto a } \\
\text { P\&D }\end{array}$} & Criação de serviço & Invenção de serviço \\
\hline & Titular: Contratante & Titular: Contratante \\
\hline & $\begin{array}{c}\text { Artigo } 4^{\circ}, \text { Lei n. } \\
9.609 / 1998 \\
\end{array}$ & $\begin{array}{c}\text { Artigos 88, 89, } 92 \mathrm{e} \\
\text { 93, Lei n. 9.279/1996 } \\
\end{array}$ \\
\hline \multirow{3}{*}{$\begin{array}{l}\text { (2) Resultar da natureza } \\
\text { dos serviços para os quais } \\
\text { a pessoa foi contratada }\end{array}$} & Criação de serviço & Invenção de serviço \\
\hline & Titular: Contratante & Titular: Contratante \\
\hline & $\begin{array}{c}\text { Artigo } 4^{\circ}, \text { Lei n. } \\
9.609 / 1998 \\
\end{array}$ & $\begin{array}{c}\text { Artigos 88, 89, } 92 \mathrm{e} \\
\text { 93, Lei n. 9.279/1996 }\end{array}$ \\
\hline \multirow{3}{*}{$\begin{array}{l}\text { (3) Estar desvinculada do } \\
\text { contrato de trabalho e não } \\
\text { decorrer da utilização de } \\
\text { recursos da contratante }\end{array}$} & Criação livre & Invenção livre \\
\hline & Titular: contratada & Titular: contratada \\
\hline & $\begin{array}{c}\text { Artigo } 4 \text { o, } \$ 22^{\circ} \text {, Lei } \\
\text { n. } 9.609 / 1998\end{array}$ & $\begin{array}{c}\text { Artigos 90, } 92 \text { e 93, } \\
\text { Lei n. 9.279/1996 }\end{array}$ \\
\hline \multirow{3}{*}{$\begin{array}{l}\text { (4) Resultar da } \\
\text { contribuição pessoal da } \\
\text { contratada e de recursos* } \\
\text { da contratante }\end{array}$} & Criação comum & Invenção comum \\
\hline & $\begin{array}{l}\text { Cotitulares: } \\
\text { contratante e } \\
\text { contratada }\end{array}$ & $\begin{array}{l}\text { Cotitulares: } \\
\text { contratante e } \\
\text { contratada }\end{array}$ \\
\hline & 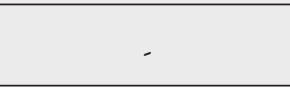 & $\begin{array}{c}\text { Artigos 91, 92 e 93, } \\
\text { Lei n. 9.279/1996 }\end{array}$ \\
\hline $\begin{array}{l}\text { Prazo de duração dos } \\
\text { efeitos do contrato }\end{array}$ & $\begin{array}{c}\text { Com o término do } \\
\text { contrato }\end{array}$ & $\begin{array}{l}12 \text { meses após o } \\
\text { término do contrato }\end{array}$ \\
\hline
\end{tabular}

* Trata-se não só de recursos em si, como também de meios, dados, informações tecnológicas, segredos industriais e de negócios, materiais, instalações ou equipamentos do contratante (empregador ou prestador de serviços) (Art. $4^{\circ}, \S 2^{\circ}$, Lei n. 9.610/1998; Art. 90, Lei n. 9.279/1996).

Fonte: adaptado de ZIBETTI, 2009, p. 108-109.

Essas regras resumidas no Quadro 2 aplicam-se também aos funcionários públicos estaduais, tanto aos pesquisadores de instituições científicas e tecnológicas como aos servidores públicos em geral. 


\section{CONCLUSÃO}

O elevado crescimento da participação de funcionários públicos no processo de desenvolvimento de programas de computador suscita a necessidade de se aprofundar o debate a respeito da titularidade dos direitos de propriedade intelectual sobre esses programas. São diversos os tipos de criações que podem resultar desse processo, como programas de computador protegidos em si por direitos de propriedade intelectual, invenções e modelos de utilidade protegidos por direitos de propriedade industrial sobre patente.

Ainda que a regra geral de atribuição da titularidade desses direitos seja a da autoria - em que o autor da criação ou invento é caracterizado como titular de direitos -, quando se trata de programas de computador desenvolvidos no marco de uma relação laboral, há alterações dessa regra que pode deslocar os direitos ao empregador.

Os programas de computador desenvolvidos com a colaboração de servidores públicos, incluindo-se os inventos a eles associados, podem ser caraterizados como "criações livres", "criações de serviço" ou "criações comuns", correspondendo à titularidade ao empregado, ao empregador ou em comum ao empregado e empregador, respectivamente. No caso em que a titularidade seja do empregador ou em comum ao empregado e empregador, a legislação assegura ao empregado justa remuneração.

No que se refere aos servidores públicos, quando a titularidade for da Administração Pública, a legislação garante ao empregado premiação de parcela - que não pode exceder a um terço - do valor das vantagens auferidas com a exploração da patente ou do registro, a título de incentivo. Cabe aos órgãos e entidades públicos regulamentar esses parâmetros.

No Estado de Santa Catarina, que possui um polo tecnológico bastante avançado no desenvolvimento de software, inclusive para a Administração Pública, não se identificam 
normas que regulem a matéria nos estatutos e regimentos dos órgãos e entidades públicos. Há somente a lei de inovação catarinense que, no entanto, estabelece somente regras aplicáveis aos pesquisadores públicos e funcionários de instituições científicas e tecnológicas do Estado.

Essa lacuna exige regulamentação estadual, de forma a se conformar com a legislação federal e assegurar a todos os servidores públicos que colaboram no desenvolvimento de programas de computador os benefícios econômicos sobre suas criações benefícios que não se limitam apenas aos pesquisadores públicos de instituições científicas e tecnológicas do Estado. Regras como essas servem de importante estímulo para os funcionários públicos contribuírem para impulsionar o desenvolvimento tecnológico e a inovação catarinense e nacional.

\begin{abstract}
This article aims to analyze the ownership of intellectual property rights on computer programs developed in collaboration with public employees from Santa Catarina. The study shows that public servants who collaborate in the development of computer programs have rights to participation in profits from its exploitation, but there are gaps in the regulation of this matter in the legislation of Santa Catarina, since the innovation law provides benefits only to public researchers from scientific and technological institutions of Santa Catarina, without treating the gains for public servants in general.
\end{abstract}

Keywords: Computer program. Public server. Intellectual property. Ownership.

\title{
REFERÊNCIAS
}

AREAS, Patrícia de Oliveira. Contratos internacionais de software: o direito moral do autor como limitante da autonomia da vontade. 2006.

Dissertação (Mestrado em Direito) - Curso de Pós-Graduação em Direito, Universidade Federal de Santa Catarina, Florianópolis, 2006. 
BARBOSA, Denis Borges. Direito da inovação: comentários à lei no 10.973/2004, Lei Federal da Inovação. Rio de Janeiro: Lumen Juris, 2006.

BRASIL. Decreto n².553, de 16 de abril de 1998. Regulamenta os arts. 75 e 88 a 93 da Lei no 9.279, de 14 de maio de 1996, que regula direitos e obrigações relativos à propriedade industrial. Disponível em: <http://www. planalto.gov.br/ccivil_03/decreto/D2553.htm> Acesso em: 10 de agosto de 2014.

BRASIL. Lei no 10.973 de 2 de dezembro de 2004. Dispõe sobre incentivos à inovação e à pesquisa científica e tecnológica no ambiente produtivo e dá outras providências. Disponível em: <http://www.planalto.gov.br/ ccivil_03/_ato2004-2006/2004/lei/110.973.htm> Acesso em: 10 de agosto de 2014.

BRASIL. Lei no 9.279 de 14 de maio de 1996. Regula os direitos e obrigações relativos à propriedade industrial. Com alterações estabelecidas pela Lei noo 10.196, de 14 de fevereiro de 2001. Disponível em: <http://www.planalto. gov.br/ccivil_03/leis/19279.htm> Acesso em: 10 de agosto de 2014.

BRASIL. Lei no 9.609 de 19 de fevereiro de 1998. Dispõe sobre a proteção de propriedade intelectual de programa de computador, sua comercialização no país e dá outras providências. Disponível em: <http://www.planalto.gov. br/ccivil_03/leis/19609.htm> Acesso em: 10 de agosto de 2014.

BRASIL. Lei no 9.610 de 19 de fevereiro de 1998. Altera, atualiza e consolida a legislação sobre direitos autorais e dá outras providências. Disponível em: <http://www.planalto.gov.br/ccivil_03/leis/19610.htm> Acesso em: 10 de agosto de 2014.

BRASIL. Tribunal Superior do Trabalho. Recurso de Revista TST-RR749.341/01.5. Recorrentes: Rede Ferroviária Federal S/A e Ferrovia Centro Atlântica S/A. Recorrido: Marcos Penha Menezes. Primeira Turma. Relator: Ministro João Oreste Dalazen. Brasília, 9/8/2006. DJ 06/10/2006.

BRASIL. Tribunal Superior do Trabalho. Recurso Ordinário em Ação Rescisória TST-ROAR-752911/2001.7. Recorrente: Usiminas Mecânica S/A. Recorrido: Juan Elias Lepe Yevenes. Subseção II Especializada em Dissídios Individuais Relator: Ministro José Simpliciano Fontes de F. Fernandes. Brasília, 28/11/2006. DJ de 19/12/2006.

BRASIL. Tribunal Superior do Trabalho. Primeira Turma. Reapreciação 
de Recurso de Revista TST-RRR-1.426/79. Rel. Juiz Convocado Sebastião Machado Filho. Brasília, DJU de 25.11.88, p. 31.160.

BRASIL. Tribunal Superior do Trabalho. Quarta Turma. Agravo de Instrumento em Recurso de Revista TST-AIRR - 433/1986-001-17-00. Agravante: Companhia Vale do Rio Doce. Agravado: Francisco Chagas Marques dos Santos. Relator: Milton de Moura França. Brasília, 14/4/2004. DJ de 30/04/2004.

CABANELLAS DE LAS CUEVAS, Guillermo. Derecho de las patentes de invención. 2ed. Buenos Aires, 2004.

CENTRO TÉCNICO AEROESPACIAL (CTA). Instituto de Estudos Avançados (IEAv). Atividades de Pesquisa e Desenvolvimento. São José dos Campos, SP: IEAv/CTA, vol. 1, 2008, p. 16. Disponível em: <http:// portal.ieav.cta.br/wp-content/uploads/caderno_atividades/Caderno_de_ Atividades_2008.pdf> Acesso em 10 de agosto de 2014.

EUROPEAN PATENT OFFICE (EPO). Espacenet. Patent search. Disponível em: <http://www.epo.org/searching/free/espacenet.html> Acesso em: 12 de agosto de 2014.

FISCHER, Frank. O Regime de copropriedade em patentes. Disponível em: <www.dannemann.com.br/files/FFI_Regime_de_CoPropriedade_em_ Patentes.pdf $>$. Acesso em: 10 de julho de 2014.

GEIGER, Christophe; Hilty, R.M. Patenting Software? A Judicial and Socio-Economic Analysis. In: IIC, 2005, Vol. 36, p. 615-647.

HUGUET, André. L'ordre public et les contrats d'exploitation du droit d'auteur. Paris: LGDJ, 1962.

LUPI, André Lipp Pinto Basto. Proteção Jurídica do Software: Eficácia e Adequação, Ed. Síntese, 1998.

MIRANDA, Pontes de. Tratado de Direito Internacional Privado. 4 ed. São Paulo: Revista dos Tribunais, 1983.

PIMENTEL, Luiz Otávio. Propriedade Intelectual e Universidade: aspectos gerais. Florianópolis: Fundação Boiteux, 2005.

PIMENTEL, Luiz Otávio. SILVA, Cláudio Eduardo Regis de Figueiredo e. Conceito jurídico de software, padrão proprietário e livre: políticas públicas. Sequência (Florianópolis) [online]. 2014, n.68, pp. 291-329. 
POLLAUD-DULIAN, Frédéric. Le Droit D'Auteur. Paris: Economica, 2005.

SAIZ GARCÍA, Concepción. Objecto y sujeto del derecho de autor. Valencia: Tirant lo Banch, 2000.

SANTA CATARINA (BRASIL). Constituição do Estado de Santa Catarina de 1989 Disponível em: <http://www.alesc.sc.gov.br/portal/legislacao/ docs/constituicaoEstadual/CESC_16_11_2009.pdf>. Acesso em 10 de julho de 2014.

SANTA CATARINA (BRASIL). Lei no 14.328, de 15 de janeiro de 2008. Dispõe sobre incentivos à pesquisa científica e tecnológica e à inovação no ambiente produtivo no Estado de Santa Catarina e adota outras providências. Disponível em: <http://fapesc.sc.gov.br/ arquivos/03092009lei_inovacao.pdf >. Acesso em 10 de julho de 2014.

SANTA CATARINA (BRASIL). Lei no 6.745, de 28 de dezembro de 1985. Estatuto dos Servidores Públicos Civis do Estado de Santa Catarina. Disponível em: <http://www.sea.sc.gov.br/index.php?option=com_ docman\& task $=$ cat_view\& $g i d=30 \&$ Itemid=64\&lang $=>$. Acesso em 10 de julho de 2014.

SILVA, C. E. R. F. Propriedade intelectual de programa de computador desenvolvido para utilização na administração pública: estudo de caso. Tese (Doutorado em Direito) - Programa de Pós-Graduação em Direito, Universidade Federal de Santa Catarina, Florianópolis, 2013.

VÁZQUEZ LÉPINETTE, Tomás. La cotitularidad de los bienes inmateriales. Valencia: Tirant lo Blanch, 1996.

VILLALBA, Carlos A.; LIPSZYC, Delia. El derecho de autor en la Argentina. Buenos Aires: La Ley, 2001.

WACHOWICZ, Marcos. Propriedade intelectual do software $\mathcal{E}$ revolução da tecnologia da informação. Curitiba, Juruá 2004.

WORLD INTELLECTUAL PROPERTY ORGANIZATION (WIPO). International Patent Classication (IPC) Official Publication. Disponível em: <http://ipc.inpi.gov.br/ipcpub/\#refresh=page> Acesso Em: 10 de agosto de 2014.

ZIBETTI, Fabíola Wüst. A titularidade sobre os bens imateriais. 2008.

Dissertação (Mestrado em Direito) - Curso de Pós-Graduação em Direito, Universidade Federal de Santa Catarina, Florianópolis, 2008. 
ZIBETTI, F. W. A titularidade de direitos de propriedade intelectual. In: Luiz Otávio Pimentel. (Org.). A proteção jurídica da propriedade intelectual de software: noções básicas e temas relacionados. Florianópolis: FIESC/ IELSC, 2009, v. 2, p. 81-122. 